\title{
In Situ Temperature-Time Effect on MetA-S-SIMS
}

\author{
Roel De Mondt and Luc Van Vaeck \\ Department of Chemistry, University of Antwerp, Wilrijk, Belgium
}

Jens Lenaerts
Agfa-Gevaert N.V, Mortsel, Belgium

Metal-assisted (MetA) static secondary ion mass spectrometry (S-SIMS) is one of several ion yield enhancing methods developed for S-SIMS in the last decades. MetA-S-SIMS uses a very thin coating of gold or silver on the sample. Earlier experiments revealed dependence of the ion yield enhancement on the applied metal, the nature of the studied sample, the time after metallization, and the heating temperature (ex situ, i.e., under atmospheric pressure). This paper reports on the effects of time and temperature when samples are heated to temperatures between 30 and $80^{\circ} \mathrm{C}$ inside the S-SIMS vacuum chamber (in situ). Thick layers of poly(vinylbutyral-co-vinylalcohol-co-vinylacetate) (PVB) containing dihydroxybenzophenone (DH$\mathrm{BPh}$ ) were coated with a nm-thin-layer of gold. The S-SIMS analysis was performed over a period of several hours while samples were kept at a constant elevated temperature. Compared to ex situ heating in an oven, heating in the analysis chamber provided more rapid signal enhancement, but the magnitude of the enhancement was less (by a factor of two). Furthermore, additional experiments on ex situ heated samples revealed that storage of samples with enhanced ion yields at $-8{ }^{\circ} \mathrm{C}$ is not sufficient to "stabilize" the enhancement. A steep decrease of the ion yields was observed as a function of time after 2.5 h. (J Am Soc Mass Spectrom 2007, 18, 382-384) (C) 2007 American Society for Mass Spectrometry

$\mathrm{T}$ The continuing search for improved detection limits in static secondary ion mass spectrometry (S-SIMS) has triggered exploration of several approaches for ion yield enhancement, such as the deposition of (sub)-monolayers on noble metal substrates [1], polyatomic primary ion bombardment [2-6], and samples in matrices typically used in matrix assisted laser desorption/ionization (MALDI) MS [7]. The recent MetA-S-SIMS methodology is based on the deposition of a nm-thick gold or silver layer on the sample via evaporation or sputtering [8-10]; a variant uses metal nanoparticle deposition [11]. The method has been successfully applied in several fields ranging from biological and polymer samples to paper research [12-16].

In contrast to the use of MALDI-matrices or monolayers on noble metal substrates, MetA-S-SIMS does not require dissolution of the sample. Moreover, the metal layer facilitates charge compensation for thick insulating samples, and often electron flooding and the associated risk of sample damage [17] can be avoided completely [8]. However, more research is

Published online November 13, 2006

Address reprint requests to R. De Mondt, Department of Chemistry (CDE), Universiteitsplein 1, 2610 Wilrijk, Belgium. E-mail: roel.demondt@ua.ac.be needed to develop and understand the MetA-S-SIMS phenomenon. Problems arise with the detection of components with molecular weight $>\mathrm{kDa}$ [8]. Expectedly, the ion yield enhancement not only depends on the analyte under study [16] and the applied metal $[10,18]$ but also on the specific sample in which it occurs. Examples hereof include the suppression of the $\mathrm{Ca}^{+}$detection in paper fibers [13], different ion yield enhancement factors for positive and negative ions from the same analyte [10]. The apparent sensitivity of the ion yield enhancement on the exact conditions used for sample preparation and storage [18] aggravates the problem.

Previous experiments on gold or silver coated samples of carbocyanine dye and DHBPh in PVB, kept at temperatures between -8 and $80^{\circ} \mathrm{C}$ during up to 1 mo before analysis, have shown that the yield increase goes through a maximum after between $1 \mathrm{~h}$ and $16 \mathrm{~d}$, depending on the temperature [19]. To the best of our knowledge, this paper is the first one to report on the ion yield enhancement for samples heated in situ, i.e., inside the S-SIMS analysis chamber under vacuum conditions of $10^{-8} \mathrm{mbar}$, to different temperatures between 30 and $80^{\circ} \mathrm{C}$ and analyzed at regular intervals during a period of several hours. Additionally, comparative experiments using ex situ heating, i.e., in a con- 


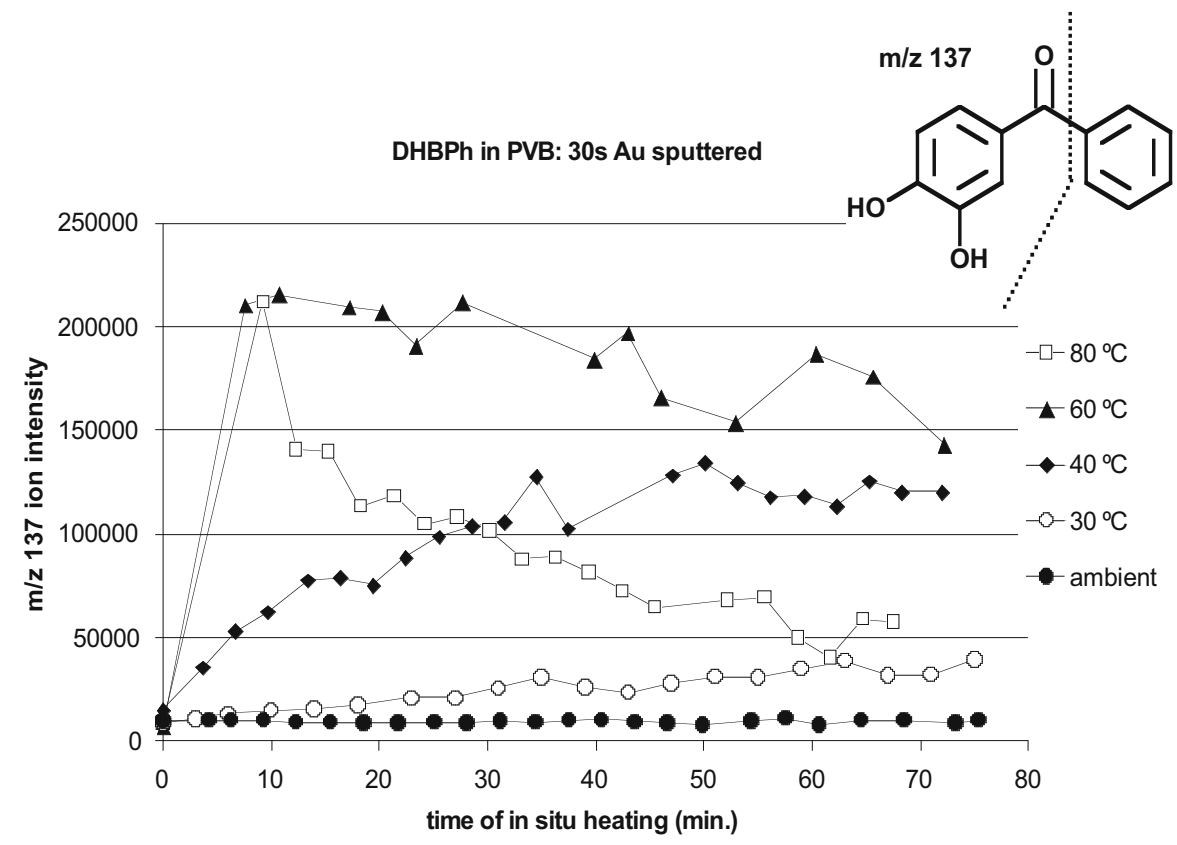

Figure 1. Ion intensities of $\mathrm{m} / \mathrm{z} 137$ from samples of gold-coated DHBPh in PVB, heated in situ (i.e., inside the S-SIMS analysis chamber) at $30,40,60$, and $80^{\circ} \mathrm{C}$ as a function of the heating time.

ventional oven under atmospheric pressure, have been carried out.

\section{Experimental}

Polymer films with a wet thickness of $100 \mu \mathrm{m}$ were cast from solutions of 1\% (wt/wt) DHBPh and 10\% (wt/wt) PVB in 2-butanone on test grade silicon wafers (Montco Silicon, Spring City, PA) using a K Hand coater (RK Print Coat Instruments Ltd., Litlington, UK). A gold layer was deposited by sputter coating (Bal-TEC SCD005, Pfeiffer, Vaduz, Liechtenstein) for $30 \mathrm{~s}$ in 0.05 mbar Ar using a current of $60 \mathrm{~mA}$ and at a sample distance of $5 \mathrm{~cm}$. The samples were immediately mounted in the Ion-TOF SIMS IV instrument (Ion-TOF, Münster, Germany) using the optional temperature programmable cryo-stage. Sample heating was performed with this stage to $30,40,60$, and $80^{\circ} \mathrm{C}$ (maximum output power $60 \%$ ), on a Eurotherm 2132 PID temperature Controller (Eurotherm Controls Ltd., Worthing, UK). Analysis was performed with $25 \mathrm{keV}$ $\mathrm{Ga}^{+}$ion pulses of $\sim 1 \mathrm{~ns}$. Mass spectra up to $\mathrm{m} / \mathrm{z} 850$ were recorded from a sample area of $100 \times 100 \mu \mathrm{m}^{2}$ using $2.8 \times 10^{12}$ primary ions $\mathrm{cm}^{-2}$. Each sample was analyzed several times during a period of up to more than $1 \mathrm{~h}$. For every data point, a different randomly selected area was analyzed.

\section{Results and Discussion}

Figureü1üsurveysütheüintensityüofütheücharacteristic fragment at $m / z$ 137, measured with S-SIMS from samples at $30,40,60$, or $80^{\circ} \mathrm{C}$ for up to $75 \mathrm{~min}$. These samples were heated in situ (in vacuum). The first data point (at time $=0$ ) is the ion intensity at ambient temperature; the second represents the intensity when the specific analysis temperature had been reached (30, 40,60 , and $80^{\circ} \mathrm{C}$, respectively). The next data points were taken at this same temperature after the indicated time intervals. The ion intensity-time profiles for low temperatures such as 30 or $40^{\circ} \mathrm{C}$ show an initially fast increase of the signals towards a constant level that is higher for 40 than for $30^{\circ} \mathrm{C}$. Going to $60{ }^{\circ} \mathrm{C}$ means that the secondary ion intensity increases even more dramatically in the first $250 \mathrm{~s}$ and slowly decreases afterwards to reach a similar value as for the samples kept at $40{ }^{\circ} \mathrm{C}$. The thermal inertia of the sample holder prevents measurements at short times and temperatures from $60{ }^{\circ} \mathrm{C}$ onwards. As a result, the time profile of the ion intensities from samples at $80^{\circ} \mathrm{C}$ only shows a relatively fast decay towards a final value lower than that seen at 40 and $60{ }^{\circ} \mathrm{C}$. These data suggest that a significant difference exists in the way the surface components are reorganized. Moreover, the fragment ion generation is improved for all temperatures studied. Interestingly, heating the sample holder with and without additional cooling with liquid nitrogen gives time profiles that are very similar in shape but shifted to higher intensities (typically a factor 2 to 3 for the maximum intensities) when liquid nitrogen was used, possibly as a result of a slight improvement of the local vacuum.

Similar results were obtained from a sample of a carbocyanineüdyeü(structureügivenünüreferenceư[19])ün PVB, which was analyzed at a temperature of $60^{\circ} \mathrm{C}$ (with liquid nitrogen cooling), in which case the signal was enhanced by a factor of 35 after $\sim 1 \mathrm{~h}$ at this temperature. It confirms our experience that each ana- 


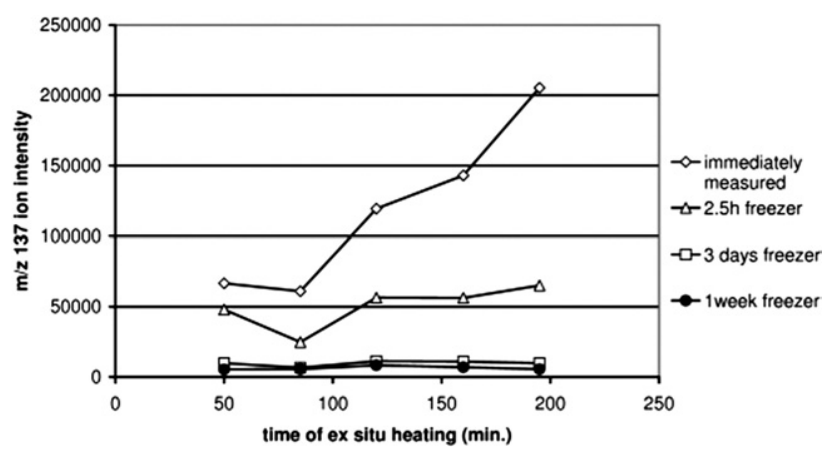

Figure 2. Ion intensities of $\mathrm{m} / \mathrm{z} 137$ from samples of gold-coated $\mathrm{DHBPh}$ in polyvinylbutyral, ex situ heated at $40^{\circ} \mathrm{C}$ for a period between 50 and $200 \mathrm{~min}$ and immediately measured or stored up to $1 \mathrm{wk}$ at $-8^{\circ} \mathrm{C}$ as a function of time

lyte and matrix requires its own optimization of temperature and heating time.

Comparative experiments were performed with sample heating under atmospheric conditions. Experiments were restricted to low temperatures to avoid complications due to extensive surface oxidation and degradation. Ex situ heating and analysis immediately afterüheatingü(cf.üdiamondücurveüinüFigureü2)üyields again a substantial increase of the ion yields as seen for the sample heating in vacuum conditions. However, maximum ion intensities recorded from sufficiently long heated samples are a factor 2 higher for treatment ex situ in comparison with that in vacuum. Interestingly, when the temporarily heated samples are stored at $-8{ }^{\circ} \mathrm{C}$ for a period from $2.5 \mathrm{~h}$ to $3 \mathrm{~d}$ and $1 \mathrm{wk}$ (triangle,ürectangle,üandücircleücurveünüFigureỉ), üsubsequent analysis shows further changes in the ion yields. The characteristic ion intensities tend to become similar, regardless of the duration of the initial heating step (and the initial ion yield differences). It looks like the surface reorganizes to the same state.

\section{Conclusions}

The simple idea of using the temperature programmable cryo-stage for heating gold covered samples during a given time inside the vacuum chamber before S-SIMS analysis is found to be very practical. At least for the system studied, gentle heating $\left(40^{\circ} \mathrm{C}\right)$ of the sample in vacuum allows the ion yield to be maximized within about half an hour. On the other hand, the experiments also reveal involvement of an extremely complex physico-chemistry. For instance, the dependence of the ion yield on the duration of the heating in vacuum or under atmospheric pressure follows a perfectly similar profile but on a different time scale. However, the yield increase for vacuum heated samples remains a factor 2 under that attainable by heating the sample under atmospheric conditions for $3 \mathrm{~h}$. Also, storage of ex situ heated samples at $-8^{\circ} \mathrm{C}$ does not stabilize the ion yield improvement for a couple of hours, making use of MetA-S-SIMS even more dependent on the time between preparation and analysis. We believe that more research needs to be performed on the fundamentals of MetA-S-SIMS so that its application does not become a process of mere trial and error.

\section{Acknowledgments}

RDM is indebted to the Institute for the Promotion of Innovation through Science and Technology in Flanders (IWT-Vlaanderen) for a Ph.D. grant. The research was funded by the Inter-University Attraction Pole Program (IUAP V), the FWO Flanders, and the Network of Excellence Nanobeams.

\section{References}

1. Hagenhoff, B. 2001; Optimization Methods: Cationization. Vickerman J. C.; Briggs, D., Eds.; In ToF-SIMS: Surface Analysis by Mass Spectrometry; IM Publication/SurfaceSpectra Ltd.: West Sussex/Manchester, p 285.

2. Gillen, G.; Roberson, S. Preliminary Evaluation of an $\mathrm{SF}_{5}^{+}$Polyatomic Primary Ion Beam for Analysis of Organic Thin Films by Secondary Ion Mass Spectrometry. Rapid Commun. Mass Spectrom. 1998, 19, 1303-1312.

3. Kötter, F.; Benninghoven, A. Secondary Ion Emission from Polymer Surfaces Under $\mathrm{Ar}^{+}, \mathrm{Xe}^{+}$, and $\mathrm{SF}_{5}^{+}$ion bombardment. Appl. Surf. Sci. 1998, 1/2, 47-57.

4. Gillen, G.; Fahey, A. Secondary Ion Mass Spectrometry Using Cluster Primary Ion Beams. Appl. Surf. Sci. 2003, 203/204, 209-213.

5. Kollmer, F. Cluster Primary Ion Bombardment of Organic Materials. Appl. Surf. Sci. 2004, 231/232, 153-158.

6. Winograd, N. The Magic of Cluster SIMS. Anal. Chem. 2005, 77 142A-149A.

7. Busch, K. L.; Hsu, B. H.; Xie, Y. X.; Cooks, R. G. Matrix Effects in Secondary Ion Mass Spectrometry. Anal. Chem. 1983, 55, 1157-1160.

8. Delcorte, A.; Médard, N.; Bertrand, P. Organic Secondary Ion Mass Spectrometry: Sensitivity Enhancement by Gold Deposition. Anal. Chem. 2002, 74, 4955-4968.

9. Delcorte, A.; Bertrand, P. Interest of Silver and Gold Metallization for Molecular SIMS and SIMS Imaging. Appl. Surf. Sci. 2004, 231/232, 250-255

10. Adriaensen, L.; Vangaever, F.; Gijbels, R. Metal-Assisted Secondary Ion Mass Spectrometry: Influence of Ag and Au Deposition on Molecular Ion Yields. Anal. Chem, 2004, 76, 6777-6785.

11. Marcus, A.; Winograd, N. Metal Nanoparticle Deposition for TOF-SIMS Signal Enhancement of Polymers. Anal. Chem. 2006, 78, 141-148.

12. Keune, K.; Boon, J. J. Enhancement of the Static SIMS Secondary Ion Yields of Lipid Moieties by Ultrathin Gold Coating of Aged Oil Paint Surfaces. Surf. Interface Anal. 2004, 36, 1620-1628.

13. Fardim, P.; Holmbom, B. TOF-SIMS Imaging: A Valuable Chemical Microscopy Technique for Paper and Paper Coatings. Appl. Surf. Sci. 2005, 249, 393-407.

14. Inoue, M.; Murase, A. Reduction of Matrix Effects in TOF-SIMS Analysis by Metal-Assisted SIMS (MetA-SIMS). Surf. Interface Anal. 2005, 37 1111-1114.

15. Nygren, H.; Malmberg, P.; Kriegeskotte, C.; Arlinghaus, H. F. Bioimaging TOF-SIMS: Localization of Cholesterol in Rat Kidney Sections. FEBS Lett. 2004, 566, 291-293.

16. Altelaar, A. F. M.; Klinkert, I.; Jalink, K. de Lange, R. P. J.; Adan, R. A. H.; Heeren, R. M. A.; Piersma, S. R. Gold-Enhanced Biomolecular Surface Imaging of Cells and Tissue by SIMS and MALDI Mass Spectrometry. Anal. Chem. 2006, 78, 734-742.

17. Gilmore, I. S.; Seah, M. P. Electron Flood Gun Damage in the Analysis of Polymers and Organics in Time-of-Flight SIMS. Appl. Surf. Sci. 2002, $187,89-100$.

18. Adriaensen, L.; Vangaever, F.; Gijbels, R. Organic SIMS: The Influence of Time on the Ion Yield Enhancement by Silver and Gold Deposition. Appl. Surf. Sci. 2004, 231/232, 256-260

19. De Mondt, R.; Adriaensen, L.; Vangaever, F.; Lenaerts, J.; Van Vaeck, L. Gijbels, R. Empirical Evaluation of Metal Deposition for the Analysis of Organic Compounds with S-SIMS. Appl. Surf. Sci. 2006, 252, 6652-6655. 